\title{
Progressively worsening paraesthesia of the left leg, gait disturbances and constipation in a 63-year-old man: diagnosis and discussion
}

\author{
Daichi Hayashi • Takenori Yonenaga • Shigeru Soshi • \\ Kunihiko Fukuda
}

Published online: 7 August 2009

(C) ISS 2009

\section{Diagnosis}

Ventral arachnoid diverticula associated with cauda equina syndrome in ankylosing spondylitis.

\section{Discussion}

Cauda equina syndrome (CES) is a well-known but rare and poorly understood complication of ankylosing spondylitis (AS). CES manifests late in the course of AS, often at a time when the AS is no longer active [1]. MRI characteristically shows an enlarged caudal thecal sac and dorsal arachnoid diverticula that fill the erosions of the bony spinal canal [2, 3]. Our patient had the typical features of CES in AS, i.e. sensory changes in lumbosacral dermatomes, constipation and moderate motor deficits in the left lower limb. However, what made this case unique was the presence of ventral arachnoid diverticula. MRI of the lumbosacral spine demonstrated localised scalloping of the posterior aspect of the L1 and L2 vertebral bodies and ventral arachnoid diverticula without neural tissue herniation. Ventral shift and adhesion of the conus medullaris and

The case presentation can be found at doi:10.1007/s00256-009-0756-0.

D. Hayashi $(\bowtie) \cdot$ T. Yonenaga $\cdot$ K. Fukuda

Department of Radiology, Jikei University School of Medicine,

3-25-8 Nishi-Shimbashi, Minato-Ku,

Tokyo 105-8461, Japan

e-mail: daichi.hayashi@jikei.ac.jp

S. Soshi

Department of Orthopedic Surgery,

Jikei University School of Medicine,

3-25-8 Nishi-Shimbashi, Minato-Ku,

Tokyo 105-8461, Japan

the cauda equina were also seen (Figs. 1, 2 in the case presentation). To date, only three cases have been reported regarding ventral dural abnormalities associated with CES in AS (Table 1) [1, 4, 5].

Arachnoid diverticula formation in AS is thought to result from an inflammatory process affecting the vertebral column [6]. In our case, the L1/2 intervertebral disc showed a high signal, similar to that of bone marrow or perivertebral fat on T1- and T2-weighted images (Figs. 1, 2 in the case presentation). These findings are thought to be a reflection of normal disc tissue being replaced by fatty bone marrow following an ossification process after severe discitis in the past [7]. This process was accompanied by destruction of cartilaginous endplates and subchondral bone plates, resulting in fusion of the L1 and L2 vertebral bodies.

The direction of arachnoid diverticula formation is thought to be dependent on the direction of the force of increased CSF pulse pressure and the "give" of the structures surrounding the spinal canal [1]. If structures posterior to the canal are firm and there is a relatively "soft" spot in the posterior aspect of the vertebral body, erosion could occur anterior to the spinal canal. In our case, we speculate, severe enthesitis of the discovertebral junction at the posterior aspect of the $\mathrm{L} 1 / 2$ vertebral bodies occurred in the past and created a "soft" spot. After the inflammatory process ceased to be active, formation of arachnoid diverticula through a dural defect at this spot occurred over many years.

Several possible mechanisms for nerve root damage have been proposed. These include inflammatory injury from arachnoiditis, gravitational traction injury resulting from the presence of arachnoid diverticula, and traumatic damage from excessive CSF pressure fluctuations caused by reduced elasticity and compliance of the caudal sac exposed to inflammatory changes $[6,8,9]$. In our case, we 


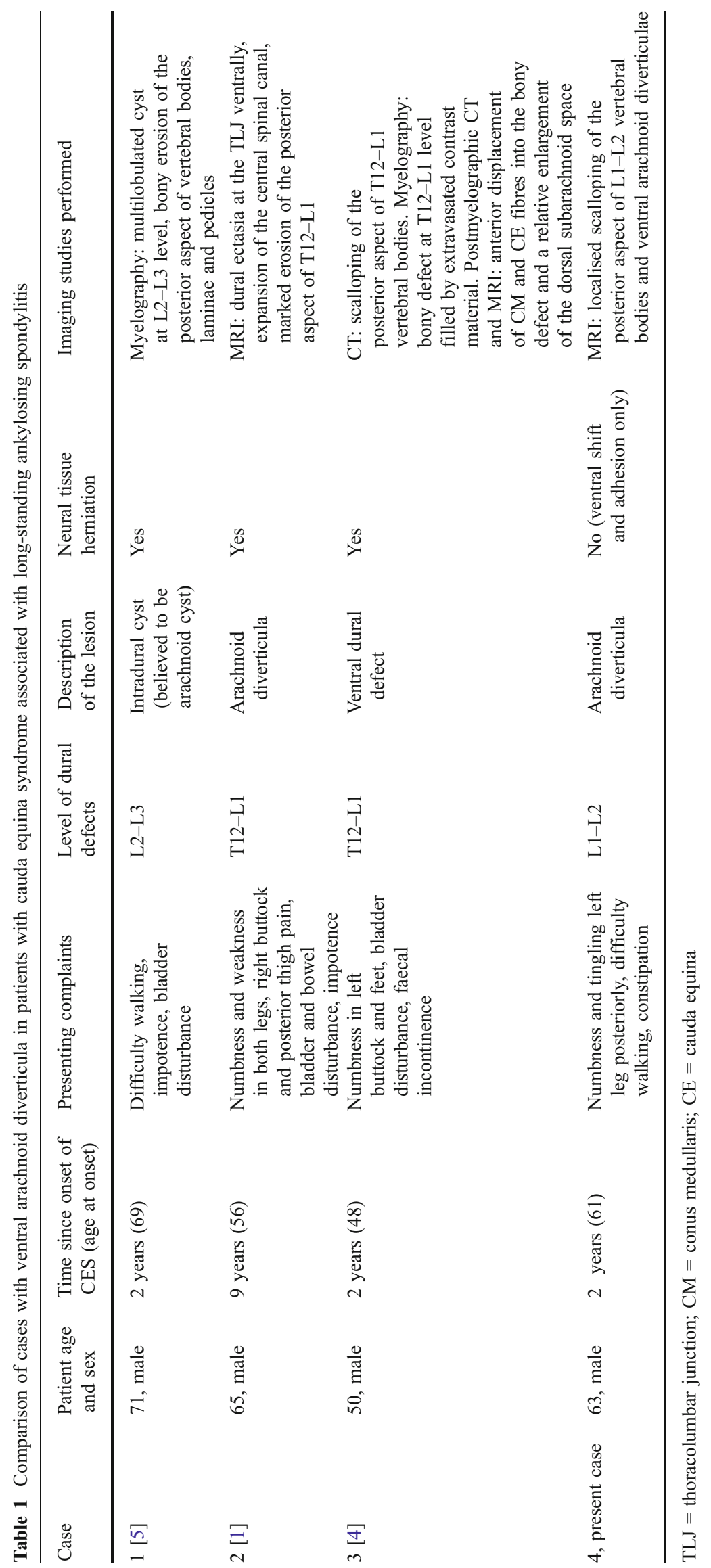


think chronic arachnoiditis at the level of L1/2 vertebral bodies in the past led to ventral shift and adhesion of the conus medullaris and the cauda equina, causing neural tissue injury and hence CES.

In conclusion, we have presented a case of CES in AS with formation of rare ventral arachnoid diverticula without neural tissue herniation. These changes seem to occur commonly at the level of the thoracolumbar junction and upper lumbar vertebrae.

\section{References}

1. Ginsberg WW, Cohen MD, Miller GM, Bartleson JD. Posterior vertebral body erosion by arachnoid diverticula in cauda equina syndrome: an unusual manifestation of ankylosing spondylitis. J Rheumatol. 1997;24:1417-20.

2. Sant SM, O'Connell D. Cauda equina syndrome in ankylosing spondylitis: a case report and review of the literature. Clin Rheuamtol. 1995;14:224-6.
3. Mitchell MJ, Sartoris DJ, Moody D, Resnick D. Cauda equina syndrome complicating ankylosing spondylitis. Radiology. 1990;175:521-5.

4. Baur A, Stabler A, Psenner K, Hamburger C, Reiser M. Imaging findings in patients with ventral dural defects and herniation of neural tissue. Eur Radiol. 1997;7:1259-63.

5. Byrne E, McNeill LA, Worthington BS. Case report: Intradural cyst with compression of the cauda equina in ankylosing spondylitis. Surg Neurol. 1985;23:162-4.

6. Shaw PJ, Allcutt DA, Bates D, Crawford PJ. Cauda equina syndrome associated with multiple lumbar arachnoid cysts in ankylosing spondylitis: improvement following surgical therapy. J Neurol Neurosurg Psychiatry. 1990;53:1076-9.

7. Malghem J, Lecouvet FE, François R, et al. High signal intensity of intervertebral calcified disks on T1-weighted MR images resulting from fat content. Skeletal Radiol. 2005;34:80-6.

8. Bilgen IG, Yunten N, Ustun EE, Oksel F, Gumusdis G. Adhesive arachnoiditis causing cauda equina syndrome in ankylosing spondylitis: CT and MRI demonstration of dural calcification and a dorsal dural diverticulum. Neuroradiol. 1999;41:508-11.

9. Bartleson JD, Cohen MD, Harrington TM. Cauda equina syndrome secondary to long-standing ankylosing spondylitis. Ann Neurol. 1983;14:662-9. 